\title{
A randomized, double-blind, placebo-controlled investigation of BCc1 nanomedicine effect on survival and quality of life in metastatic and non-metastatic gastric cancer patients
}

Maryam Hafizi ${ }^{1,2}$, Somayeh Kalanaky², Hassan moaiery ${ }^{1}$, Maryam Khayamzadeh', Sajad Noorian³, Vahid Kaveh ${ }^{4}$, Behrooz Gharib ${ }^{5}$, Hossein Foudazi ${ }^{6}$, Mohsen Razavi ${ }^{4}$, Arash Jenabian${ }^{7}$, Saeid Salimi ${ }^{4}$, Mohammad Mahdi Adib Sereshki ${ }^{4}$, Hamid Reza Mirzaei ${ }^{1}$, Afshin Zarghi ${ }^{8}$, Saideh Fakharzadeh², Mohammad Hassan Nazaran ${ }^{2^{*+}}$ and Mohammad Esmaeil Akbari ${ }^{{ }^{*+}}$

\begin{abstract}
Background: Currently, the main goal of cancer research is to increase longevity of patients suffering malignant cancers. The promising results of $\mathrm{BC} 1$ in vitro and vivo experiments made us look into the effect of $\mathrm{BC} 1$ nanomedicine on patients with cancer in a clinical trial.

Methods: The present investigation was a randomized, double-blind, placebo-controlled, parallel, and multicenter study in which 123 patients (30-to-85-year-old men and women) with metastatic and non-metastatic gastric cancer, in two separate groups of $\mathrm{BC} 1$ nanomedicine or placebo, were selected using a permuted block randomization method. For metastatic and non-metastatic patients, a daily dose of 3000 and $1500 \mathrm{mg}$ was prescribed, respectively. Overall survival (OS) as the primary endpoint and quality of life (measured using QLQ-STO22) and adverse effects as the secondary endpoints were studied.

Results: In metastatic patients, the median OS was significantly higher in BCc1 nanomedicine (174 days [95\% confidence interval (Cl) 82.37-265.62]) than in placebo (62 days [95\% Cl 0-153.42]); hazard ratio (HR): 0.5 [95\% Cl 0.25-0.98; $\mathrm{p}=0.046$ ]. In non-metastatic patients, the median OS was significantly higher in BCc1 nanomedicine (529 days [95\% $\mathrm{Cl} 393.245-664.75]$ ) than in placebo (345 days [95\% Cl 134.85-555.14]); HR: 0.324 [95\% Cl 0.97-1.07; $p=0.066$ ]. The QLQ-STO22 assessment showed a mean difference improvement of 3.25 and 2.29 ( $p$ value $>0.05$ ) in BCc1 nanomedicine and a mean difference deterioration of -4.42 and -3 ( $p$-value $<0.05)$ in placebo with metastatic and non-metastatic patients, respectively. No adverse effects were observed.
\end{abstract}

\footnotetext{
*Correspondence: mnazaran@nanochelatingtechnology.com; crc@sbmu.ac.ir

†Mohammad Hassan Nazaran and Mohammad Esmaeil Akbari contributed equally to this work

${ }^{1}$ Cancer Research Centre, Shahid Beheshti University of Medical Sciences,

Tehran, Iran

${ }^{2}$ Department of Research and Development, Sodour Ahrar Shargh

Company, Tehran, Iran

Full list of author information is available at the end of the article
} 
Conclusion: The findings of this trial has provided evidence for the potential capacity of $\mathrm{BC} C 1$ nanomedicine for treatment of cancer.

Trial registration IRCTID, IRCT2017101935423N1. Registered on 19 October 2017, http://www.irct.ir/ IRCT2017101935423N1

Keywords: BCc1 nanomedicine, Cancer, Gastric cancer, Clinical trial, Nanomedicine, Nanochelating technology

\section{Background}

Global statistics data in 2015 recorded 8.8 million deaths caused by cancer, which nearly equaled one-sixth of all deaths [1]. In 2018, 1,735,350 new cancer cases and 609,640 cancer deaths are calculated to happen in the US [2].

Among all cancers, gastric cancer has always been a major clinical challenge due to poor prognosis and inefficient treatments [3, 4]. Based on the National Cancer Database, in the United States, the overall 5-year (20082014) relative survival rate of patients having stomach cancer was about $31 \%$ [2], new stomach cancer cases were 7.2 per 100,000 people per year and the death toll was 3.2 per 100,000 people per year in 2011-2015 [5]. It is estimated that 26,240 people will be added to the previous gastric cancer patients in 2018 , which will be $1.5 \%$ of all cancer patients [5].

Approximately half of the gastric cancer occurs in East Asian countries, showing a higher mortality rate than other countries [6]. Over half of gastric cancer deaths happen in the first year of diagnosis in Iran and another $30 \%$ during the second year of diagnosis. Like other developing countries, the results show lower survival rates in Iran [7].

Currently, radiotherapy, chemotherapy, surgery, or combinations of these are being used in cancer therapies, while every one of such treatments has both pros and cons [8]. Despite the preference for surgical resection treatment in patients with cancer, chemotherapy is considered the best available treatment for recurrent and advanced cancer patients who are not suitable for surgery [4].

Although chemotherapy is widely being used in clinics, it has also had dissatisfactory outcomes, which are mostly attributed to nonspecific drug distribution to healthy tissues, indiscriminate destruction of normal cells, toxicity of conventional chemotherapeutic drugs and the capability of cancerous cells to pump out the drug using multidrug resistance mechanisms along with heterogeneity of cancer $[9,10]$.

Nanotechnology has recently revolutionized chemotherapy and cancer treatments [11]. Nanomedicine can be more effective in treatment of cancer by targeting cellular characteristics of solid tumors. Using nanomedicine in treatments can reduce the resistant clonal population of cancerous cells $[12,13]$, so in recent years, more nanomedicine drugs targeting cancer cells are being nominated to be approved by Food and Drug Administration (FDA) [10]. Having said that, nanomedicine formulations need to be revised in terms of efficacy [14].

Nanochelating is a mother technology [15] providing a high-yield technique with a wide range of scientific and technological applications [16, 17] by synthesizing nanostructures via self-assembly [18] and bottom-up method. Such nanostructures are smart molecules showing favorable reactions according to the physicochemical conditions of the environment, which will subsequently modulate the balance of contained elements in cellular microenvironments based on their designed nanostructure [19].

In our previous study, we used this technology to synthesize BCc1 [8], having chelating properties with dominant affinity for iron element. Also, we evaluated the anticancer effects of BCc1 in vivo and vitro studies.

We observed apoptosis inducing effects on cancer cells, while $\mathrm{BCc} 1$ had no negative effects on normal cells at the same concentration and also showed protecting effects against oxidative stress.

After considering intraperitoneal (IP) lethal dose (LD50) of BCc1, it was revealed that $\mathrm{BCc} 1$ increased survival in mice bearing cancer [8].

In continuation of our preclinical studies, due to short longevity of patients with gastric cancer, we tested this nanostructure on patients suffering from gastric cancer $[4,20]$. This investigation was conducted in the form of a randomized, double-blind, placebo-controlled study in two metastatic and non-metastatic gastric cancer groups to assess the overall survival (OS) and quality of life (QOL) in each. Along the study, any probable side effect pertained to the prescribed drug was also taken into account.

\section{Methods \\ Trial design}

The purpose of this study was comparing $\mathrm{BCc} 1$ nanomedicine and placebo groups.

The study was designed based on two main groups (metastatic and non-metastatic gastric cancer) that were separately divided into two sub-groups (drug and placebo). 
A randomized, double-blind, placebo-controlled, and parallel trial was conducted at Cancer Research Center of Shahid Beheshti University of Medical Sciences.

Patients were collected from the oncology center of Shohadaye Tajrish Hospital, Bu Ali, Naft Company, Imam Reza, Firouzgar, and Shahid Fayaz Bakhsh hospitals in Tehran, Iran.

All groups received BCc1 nanomedicine or placebo capsule in addition to the base treatment, so it didn't interfere in physician's protocol. The analysis report was conducted after an 18-month follow-up.

\section{Participants}

\section{Recruitment, randomization, and allocation}

Patients with adenocarcinoma gastric cancer were first invited to participate in the present study with a prior notice and then their eligibility criteria were evaluated by the researcher in charge.

Patients, the clinician, and the researcher in charge were blinded to treatment allocation. The patients were assigned to $\mathrm{BCc} 1$ nanomedicine and placebo groups based on the blocked randomization form [21].

\section{Sample collection}

Detailed trial information was all explained to patients by the researcher in charge and written informed consent was taken from all patients before enrollment. After that, all patients, already registered at Cancer Research Center of Shahid Beheshti University of Medical Sciences, were visited by the clinician, and then following the confirmation of their metastatic or non-metastatic gastric cancer using their medical records including endoscopic ultrasound (EUS), computed tomography scan (CT scan), and positron emission tomography scan (PET scan), they were sent into one of the main groups.

Finally, grouping classifications for clinical (c-stage) and post-neoadjuvant treatment (ypStage) stages for gastric adenocarcinoma were proposed for the eighth edition of the American Joint Committee on Cancer (AJCC) staging system guideline [22].

During the study, the patients who underwent a surgery and were unable to swallow did not take any drugs or placebo for 3 weeks.

\section{Inclusion criteria}

- Men and women aged 25-85.

- Patients who were able to swallow.

- Patients confirmed with adenocarcinoma gastric cancer including gastroesophageal junction.

- Patients suffering metastatic and non-metastatic gastric cancer signing the consent form.

\section{Exclusion criteria}

- Patients who declined to continue taking medicine.

- Observing adverse symptoms such as unacceptable toxicity in the patients after taking the medicine.

\section{Withdrawal criteria}

The patients were free to withdraw from the study at any time without any need to provide the reason, but they allowed the continuation of data collection.

\section{Primary outcome measurement}

- The primary main goal of the present study was OS. This period was measured from randomization time to death, irrespective of the cause.

\section{Secondary outcome measurement}

- Quality of life The secondary main goal included QOL according to the European Organization for Research and Treatment of Cancer (QLQ-ST22) questionnaire [23] once before the treatment and once after 1.5 months for patients with metastatic gastric cancer and 4 months for patients with nonmetastatic gastric cancer.

- Adverse effect Adverse effects including vomiting, nausea, neutropenia, anorexia, vital signs and hematological and biochemical tests in blood were assessed and recorded in all patients.

\section{Sample size}

63 metastatic gastric cancer patients, out of whom 33 received $\mathrm{BCc} 1$ nanomedicine and 30 received placebo, were recruited randomly for the present study. In addition, 60 non-metastatic gastric cancer patients, out of whom 30 received $\mathrm{BC} 1$ nanomedicine and 30 received placebo, were recruited randomly.

\section{Follow-up visits}

All patients were followed up on phone calls on a weekly basis and were also visited by the clinician repeatedly. In addition, patients were free to consult with the researcher in charge for any reason at any time, including the occurrence of an adverse event. 


\section{CONSORT Flow Diagram for patients with metastatic gastric cancer}

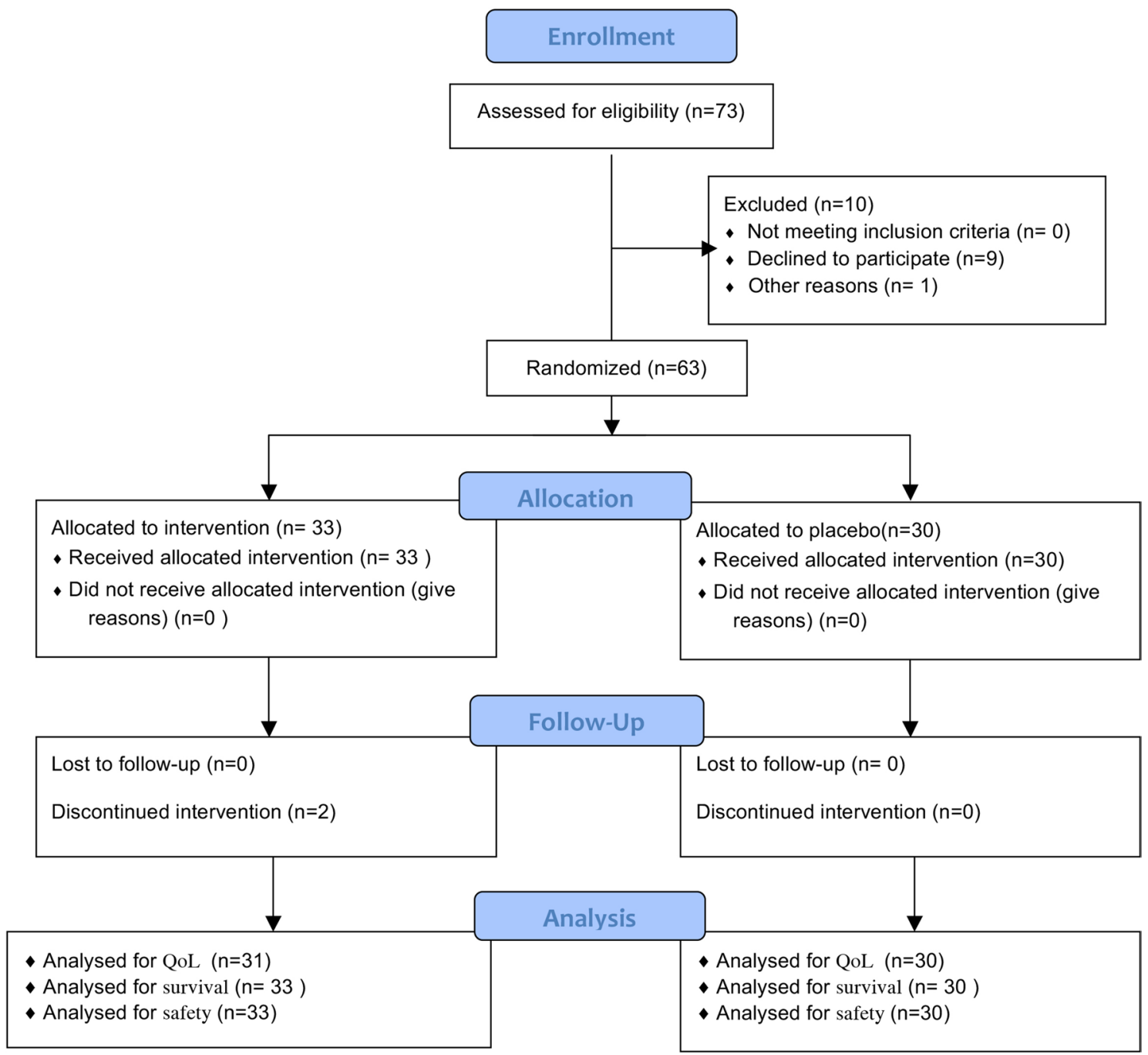

Fig. 1 Consort flow diagram for patients with metastatic gastric cancer

\section{Data collection}

The researcher in charge collected the information and checked for the missing values and consistency in patients during the study. Full details of data management procedures are available at any time.

\section{Intervention}

Both BCc1 and placebo capsules were exactly identical in terms of shape and size. The treatment doses were specified according to "Guidance for Industry Estimating the Maximum Safe Starting Dose in Initial Clinical Trials for Therapeutics in Adult Healthy Volunteers" guideline [24].

In the previous animal study, we obtained LD50 for BCc1 nanomedicne (Additional file 1) by which we acquired No Observed Adverse Effect Level (NOAEL) for clinical study. The most famous and applicable method to adjust effective animal dose to human dose is calculating the effective animal dose for body surface area based on $\mathrm{mg} / \mathrm{m}^{2}$. Therefore, we considered LD50 the reference to normalize the effective dose and then calculated it based on $\mathrm{mg} / \mathrm{m}^{2}$, we chose the lowest dose at the safe range as first-in-human (FIH) for non-metastatic patients and highest dose at the safe range as FIH for metastatic patients [24].

A daily dose of $3000 \mathrm{mg}$ was used for metastatic patients and $1500 \mathrm{mg}$ for non-metastatic patients at three servings. The patients were monthly provided with medicine free of charge, while the researcher in charge 


\section{CONSORT Flow Diagram for patients with non-metastatic gastric cancer}

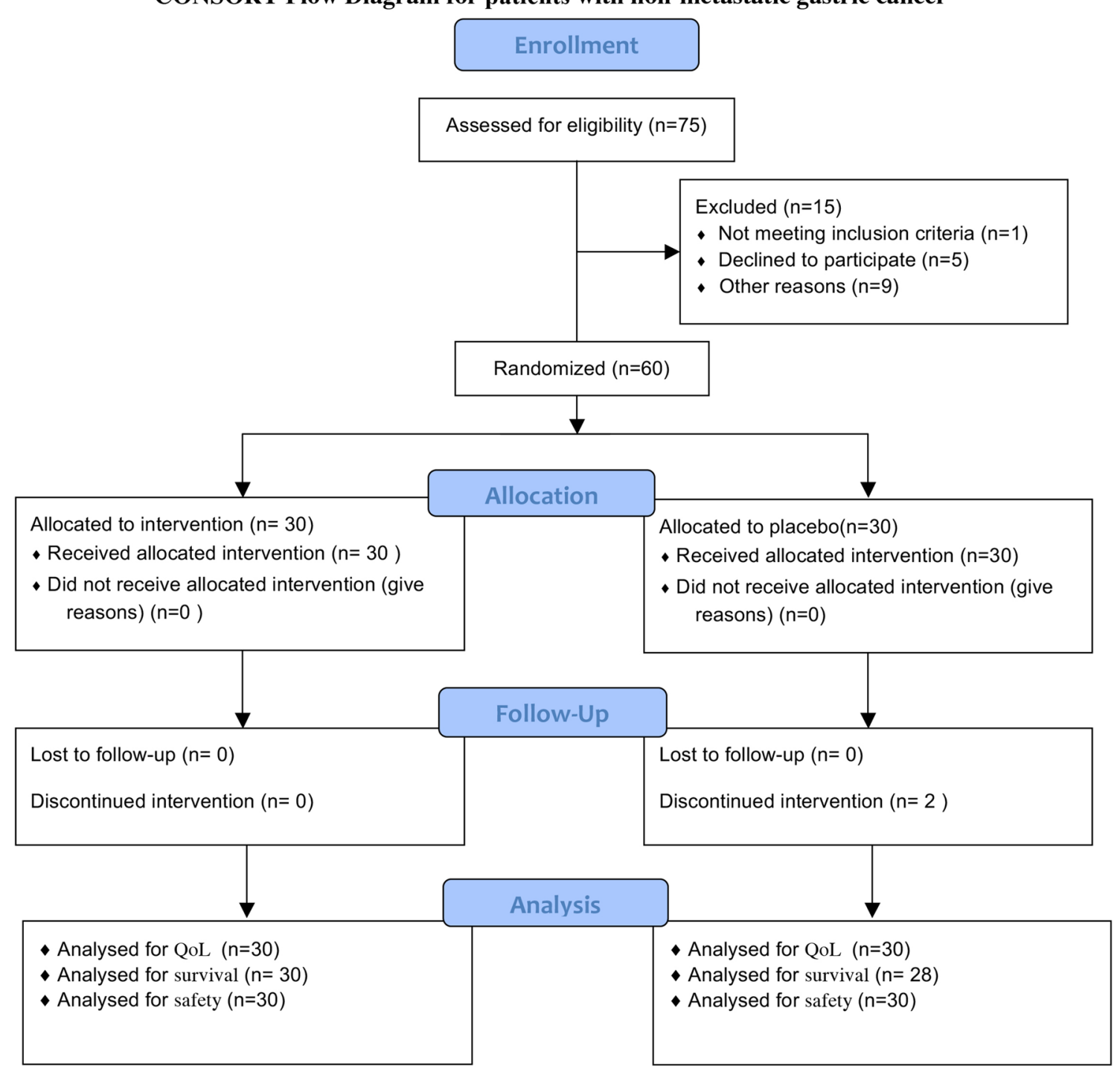

Fig. 2 Consort flow diagram for patients with non-metastatic gastric cancer

became sure the patients took the medicine in the previous months.

Active pharmaceutical ingredient (API) synthesis of BCc1 nanomedicine was done in Sodour Ahrar Shargh Company's laboratory using nanochelating technology [15] and then it was capsulized in Tehran Darou Pharmaceutical Co. in Tehran, Iran. Yet, both synthesizing and capsulizing placebo API were done in Tehran Darou Pharmaceutical Co. in Tehran, Iran.

\section{Statistical methods}

The Kaplan-Meier [25] and Lifetime Table were used for construction of survival curves, and comparisons were performed using the log-rank test [26]. Hazard ratios (HRs) and 95\% confidence interval (CI) were derived from cox proportional hazards models stratified by the two randomization stratification factors [27].

For QOL, first, the mean scores for all patients were calculated and then compared between the two groups (BCc1 nanomedicine and placebo) with Paired Samples T-Test (parametric statistic) and Wilcoxon Signed Ranks Test (non-parametric statistic) used for statistical comparison. A p-value of $\leq 0.05$ was considered significant for covariate selection. All analyses were conducted using SPSS software (version 25; SPSS Inc., Chicago, IL, USA) [28]. 
Table 1 Patients' characteristics with metastatic gastric cancer

\begin{tabular}{|c|c|c|}
\hline & $\begin{array}{l}\text { BCc1 nanomedicine } \\
(\mathrm{n}=33)\end{array}$ & $\begin{array}{l}\text { Placebo } \\
(n=30)\end{array}$ \\
\hline \multicolumn{3}{|l|}{ Age, years } \\
\hline Mean (SD) & $59.8 \pm 13$ & $61.2 \pm 12.93$ \\
\hline \multicolumn{3}{|l|}{ Weight } \\
\hline Mean (SD) & $61.68 \pm 12.24$ & $55.62 \pm 12.82$ \\
\hline \multicolumn{3}{|l|}{ Gender (n) } \\
\hline Male-female & $23-10$ & $20-10$ \\
\hline \multicolumn{3}{|l|}{ Metastatic site (n) } \\
\hline Liver & 17 & 11 \\
\hline Multiple site & 9 & 10 \\
\hline Lung & 2 & 3 \\
\hline Peritoneal carcinomatosis & 5 & 4 \\
\hline Stage $4(n)$ & 33 & 30 \\
\hline \multicolumn{3}{|l|}{ Site of involvement (n) } \\
\hline Cardia & 7 & 10 \\
\hline Antrum & 6 & 5 \\
\hline Fundus & 3 & 3 \\
\hline Greater curvature & 3 & 4 \\
\hline Lesser curvature & 4 & 3 \\
\hline Diffuse & 4 & 5 \\
\hline Intervention + chemotherapy (n) & 14 & 19 \\
\hline $\begin{array}{l}\text { Intervention }+ \text { chemotherapy }+ \\
\text { radiotherapy }(\mathrm{n})\end{array}$ & 0 & 1 \\
\hline
\end{tabular}

\section{Results}

\section{Patients' disposition and characteristics}

The patients were recruited between October 26, 2016 and May 19, 2018. The average ages for metastatic BCc1 nanomedicine and placebo groups at stage IV were $59.8 \pm 13$ and $61.2 \pm 12.93$, respectively, and in non-metastatic $\mathrm{BCc} 1$ and placebo groups at stages I, II, and III the average ages were $65 \pm 10.5$ and $61 \pm 11.4$, respectively.

As shown in Figs. 1 and 2, the number of all patients who were initially recruited on a random basis was 148 , out of whom 25 were excluded from the study because of ineligibility, incomplete histological confirmation, among other reasons (These tables are prepared according to Consolidated Standards of Reporting Trials Form) [29]. The metastatic and non-metastatic patients' characteristics are shown in Tables 1 and 2.

\section{Overall survival}

As shown in Table 3A, in metastatic patients, the median OS in BCc1 nanomedicine and placebo patients was 174 [95\% CI 82.37-265] and 62 days [95\% CI 0-153.42], respectively, thus the results showed that in metastatic patients who took $\mathrm{BCc} 1$ capsules, the median OS was 112 days significantly higher than that of patients who took placebo capsules; HR: 0.5 [95\% CI 0.25-0.98; $\mathrm{p}=0.046]$. Kaplan-Meier diagram of survival and hazard function diagram of metastatic patients are shown in Fig. 3a, b.

Likewise, as shown in Table $3 \mathrm{~A}$, in non-metastatic patients the median $\mathrm{OS}$ in $\mathrm{BCc} 1$ and placebo patients was 529 [95\% CI 393-664] and 345 days [95\% CI 134.85555.147], respectively, thus the results showed that in non-metastatic patients who took BCc1 capsules, the median OS was 184 days significantly higher than that of patients who took placebo capsules; HR: 0.324 [95\% CI 0.97-1.07; $\mathrm{p}=0.066$ ]. Kaplan-Meier diagram of survival and hazard function diagram of non-metastatic patients are shown in Fig. 4a, b.

As shown in Table 3B, in metastatic patients, $48.5 \%$ of patients in BCc1 nanomedicine group and $63.3 \%$ in placebo group, and in non-metastatic patients, $12.9 \%$ in BCc1 nanomedicine group and $29.6 \%$ in placebo group died during the study.

In the same study, we did an analysis to investigate patients' OS who received $\mathrm{BCc} 1$ nanomedicine or placebo and chemotherapy (three types of regimens FOLFOX, DCF, and FLOT) simultaneously.

As shown in Table 4A, in metastatic patients, the median OS in BCc1 and placebo patients was 302 [95\% CI 40.87-563.13] and 107 days [95\% CI 0-214.98], respectively, while they underwent chemotherapy at the same time. The results revealed that in metastatic patients who took BCc1 capsules and simultaneously underwent chemotherapy, the median OS was 195 days longer, although not significantly, than the median OS of those who received placebo capsules and chemotherapy at the same time; HR: 0.589 [95\% CI 0.212-1.64; $\mathrm{p}=0.311]$. Kaplan-Meier diagram of survival and hazard function diagram of metastatic patients who received $\mathrm{BCc} 1$ nanomedicine or placebo and underwent chemotherapy at the same time are shown in Fig. 5a, b.

However, as shown in Table $4 \mathrm{~A}$, in non-metastatic patients, the median $\mathrm{OS}$ in $\mathrm{BCc} 1$ and placebo patients was 482 and 265 days [95\% CI 210.57-319.42], respectively, thus in non-metastatic patients who took $\mathrm{BCc} 1$ capsules and simultaneously underwent chemotherapy, the median OS was 217 days significantly longer than the median OS of those who received placebo and chemotherapy at the same time; HR: 0.019 [95\% CI 0-0.065; $p=0.207]$. Kaplan-Meier diagram of survival and hazard function diagram of non-metastatic patients who received the interventions ( $\mathrm{BCc} 1$ nanomedicine or placebo) and underwent chemotherapy at the same time are shown in Fig. 6a, b.

As shown in Table 4B, in metastatic patients, $50 \%$ of patients in $\mathrm{BCc} 1$ nanomedicine and $53 \%$ in placebo, and in non-metastatic patients, no patients in $\mathrm{BCc} 1$ 
Table 2 Patients' characteristics with non-metastatic gastric cancer

\begin{tabular}{|c|c|c|}
\hline & $\begin{array}{l}\text { BCc1 nanomedicine } \\
(\mathrm{n}=30)\end{array}$ & $\begin{array}{l}\text { Placebo } \\
(n=30)\end{array}$ \\
\hline \multicolumn{3}{|l|}{ Age, years } \\
\hline Mean (SD) & $65 \pm 10.5$ & $61 \pm 11.4$ \\
\hline \multicolumn{3}{|l|}{ Weight } \\
\hline Mean (SD) & $62 \pm 14$ & $59 \pm 11$ \\
\hline \multicolumn{3}{|l|}{ Gender (n) } \\
\hline Male-female & $20-10$ & $14-19$ \\
\hline \multicolumn{3}{|l|}{ Stage (n) } \\
\hline । & 3 & 1 \\
\hline$\|$ & 3 & 8 \\
\hline III & 19 & 13 \\
\hline \multicolumn{3}{|l|}{ Site of involvement (n) } \\
\hline Cardia & 10 & 9 \\
\hline Antrum & 9 & 6 \\
\hline Fundus & 0 & 3 \\
\hline Greater curvature & 3 & 1 \\
\hline Lesser curvature & 7 & 5 \\
\hline Diffuse & 2 & 2 \\
\hline Intervention + chemotherapy (n) & 12 & 20 \\
\hline $\begin{array}{l}\text { Intervention chemotherapy + } \\
\text { radiotherapy (n) }\end{array}$ & 1 & 2 \\
\hline
\end{tabular}

nanomedicine and $35 \%$ in placebo died during the study, while patients of these groups received the interventions (BCc1 nanomedicine or placebo) and underwent chemotherapy at the same time.

In the same study, we did an analysis to investigate patients' OS who received only interventions (BCc1 nanomedicine or placebo) without undergoing chemotherapy.
As shown in Table 5A, the results revealed that in metastatic patients who only took $\mathrm{BCc} 1$ capsules, the median OS was 122 days significantly longer than the median OS of those who received only placebo capsules. Kaplan-Meier diagram of survival and hazard function diagram of metastatic patients who received only intervention (BCc1 nanomedicine or placebo) are shown in Fig. 7a, b.

On the other hand, as shown in Table 5A, in nonmetastatic patients who only took placebo capsules, the median OS was 12 days longer, although not significantly, than the median OS of those who received BCc1. Kaplan-Meier diagram of survival and hazard function diagram of non-metastatic patients who received only intervention ( $\mathrm{BCc} 1$ nanomedicine or placebo) are shown in Fig. 8a, b.

As shown in Table 5B, in metastatic patients, $49 \%$ of patients in $\mathrm{BCc} 1$ nanomedicine and $63 \%$ in placebo, and in non-metastatic patients, $13 \%$ in $\mathrm{BCc} 1$ nanomedicine and $30 \%$ in placebo died during the study, while patients of these groups received only the medicine $(\mathrm{BCc} 1$ nanomedicine or placebo), without undergoing chemotherapy.

The results of Cox multivariate regression model are shown in Table 6. In part A of Table 6, HR of BCc1 nanomedicine equals 0.476 [95\% CI 0.24-0.96; $\mathrm{p}=0.039$ ]. This value of $H R$ indicates that in metastatic patients, the hazard of mortality for those who took $\mathrm{BCc} 1$ nanomedicine is 0.476 times more than that of those who took placebo. Likewise, in part A of Table 6, HR of chemotherapy equals 0.737 [95\% CI $0.37-1.47$; $\mathrm{p}=0.388]$. This value of HR indicates that in metastatic patients, the hazard of mortality for those who underwent chemotherapy is 0.737 times more than that of those who did not receive chemotherapy.

Table 3 (A) Median of overall survival analysis in all metastatic and non-metastatic gastric cancer patients in the whole study. (B) Death percentage analysis in all metastatic and non-metastatic gastric cancer patients in the whole study

\begin{tabular}{|c|c|c|c|c|}
\hline \multirow{2}{*}{$\begin{array}{l}\text { Group } \\
\text { Total number }\end{array}$} & \multicolumn{2}{|l|}{ Metastatic } & \multicolumn{2}{|c|}{ Non-metastatic } \\
\hline & $\mathrm{BCC} 1(n=33)$ & Placebo $(n=30)$ & $\mathrm{BCc} 1(n=30)$ & Placebo $(n=30)$ \\
\hline \multicolumn{5}{|l|}{ (A) Median of overall survival analysis } \\
\hline Median (days) & 174 & 62 & 529 & 345 \\
\hline Std. error & 46.748 & 46.643 & 69.263 & 107.218 \\
\hline Median 95\% Cl (lower) & 82.374 & 0.000 & 393.245 & 134.854 \\
\hline Median 95\% Cl (upper) & 265.626 & 153.421 & 664.755 & 555.146 \\
\hline $\begin{array}{l}\text { P-value for test of equality of survival } \\
\text { distributions }\end{array}$ & 0.04 & & 0.05 & \\
\hline $\begin{array}{l}\mathrm{HR} \\
\text { (BCc1/Placebo) }\end{array}$ & 0.5 & & 0.324 & \\
\hline \multicolumn{5}{|l|}{ (B) Death percentage analysis } \\
\hline Death percentage & $48.5 \%$ & $63.3 \%$ & $12.9 \%$ & $29.6 \%$ \\
\hline
\end{tabular}

Test of equality of survival distributions (for Bcc1 and placebo groups) assay with Log Rank (Mantel-Cox) 


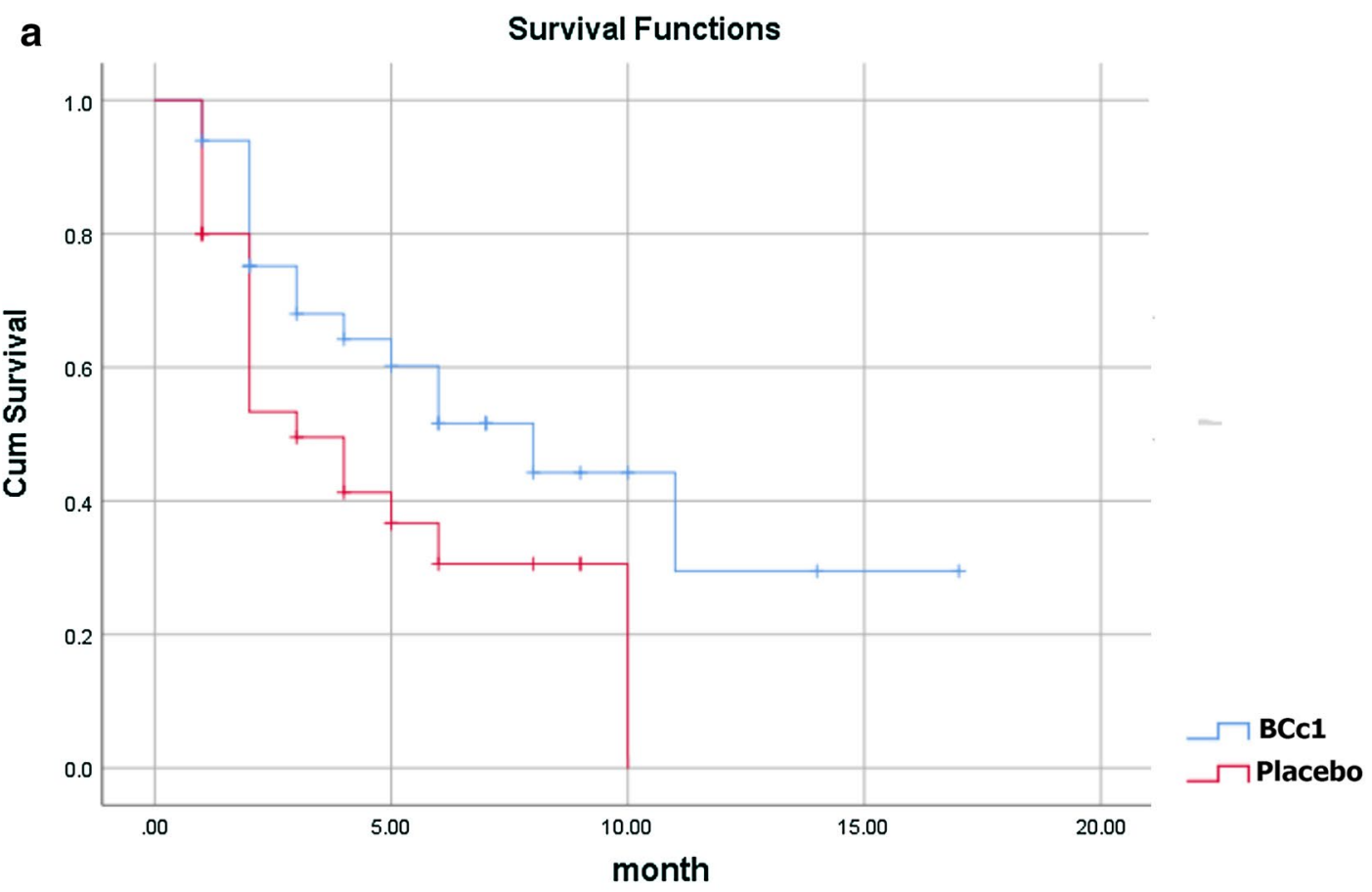

Hazard Function

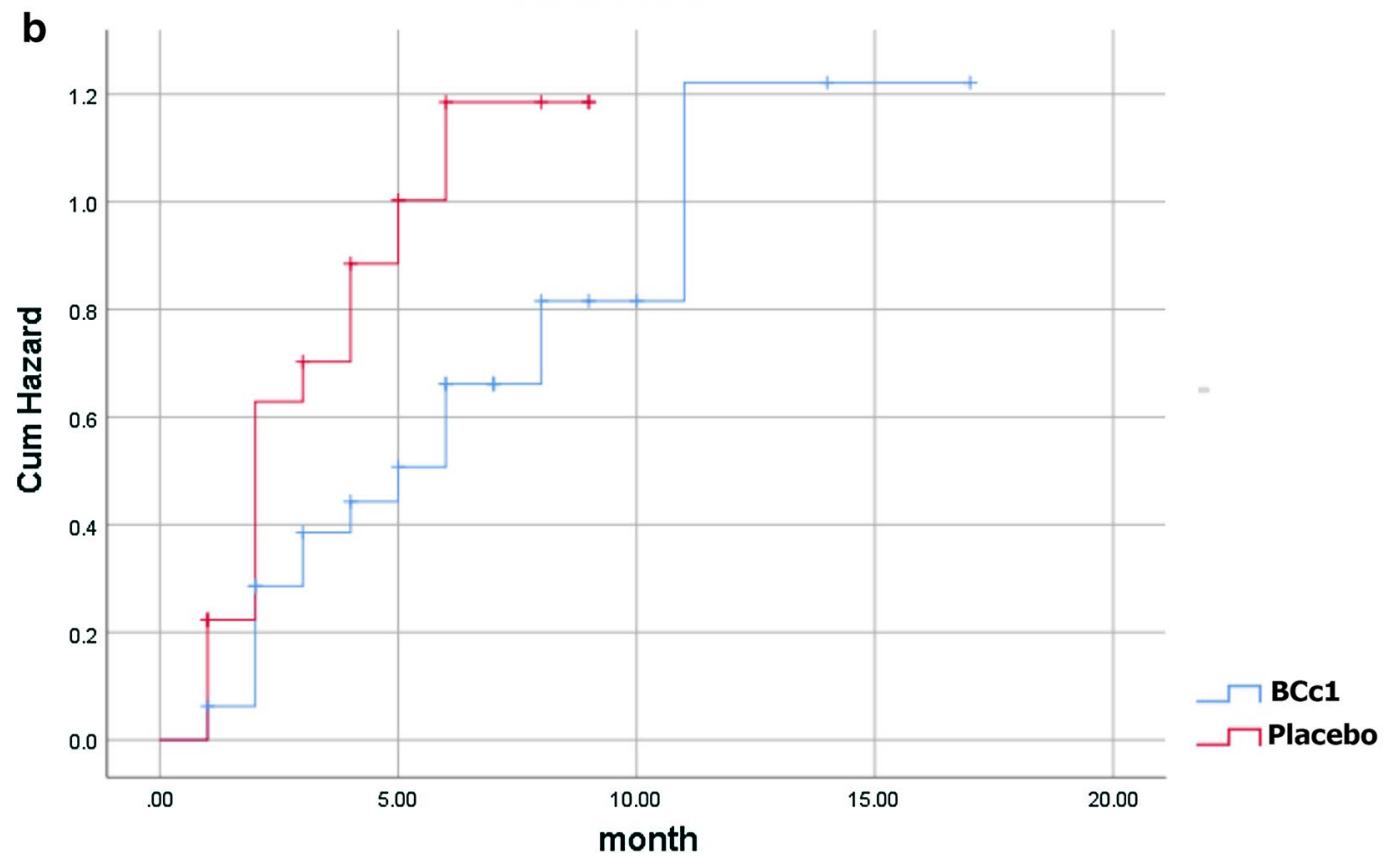

Fig. 3 a Kaplan-Meier diagram of survival. b Hazard function diagram in metastatic patients (Lifetime tables of hazard and survival for patients who received $\mathrm{BC} 1$ nanomedicine show a higher survival and lower hazard than patients who received placebo)

As shown in part B of Table 6, HR of BCc1 equals 0.268 [95\% CI $0.07-1.04 ; \mathrm{p}=0.057$ ]. This value of $\mathrm{HR}$ indicates that in non-metastatic patients, the hazard of mortality for those who took BCc1 nanomedicine is 0.268 times more than that of those who took placebo. Likewise, in part B of Table 6, HR of chemotherapy 

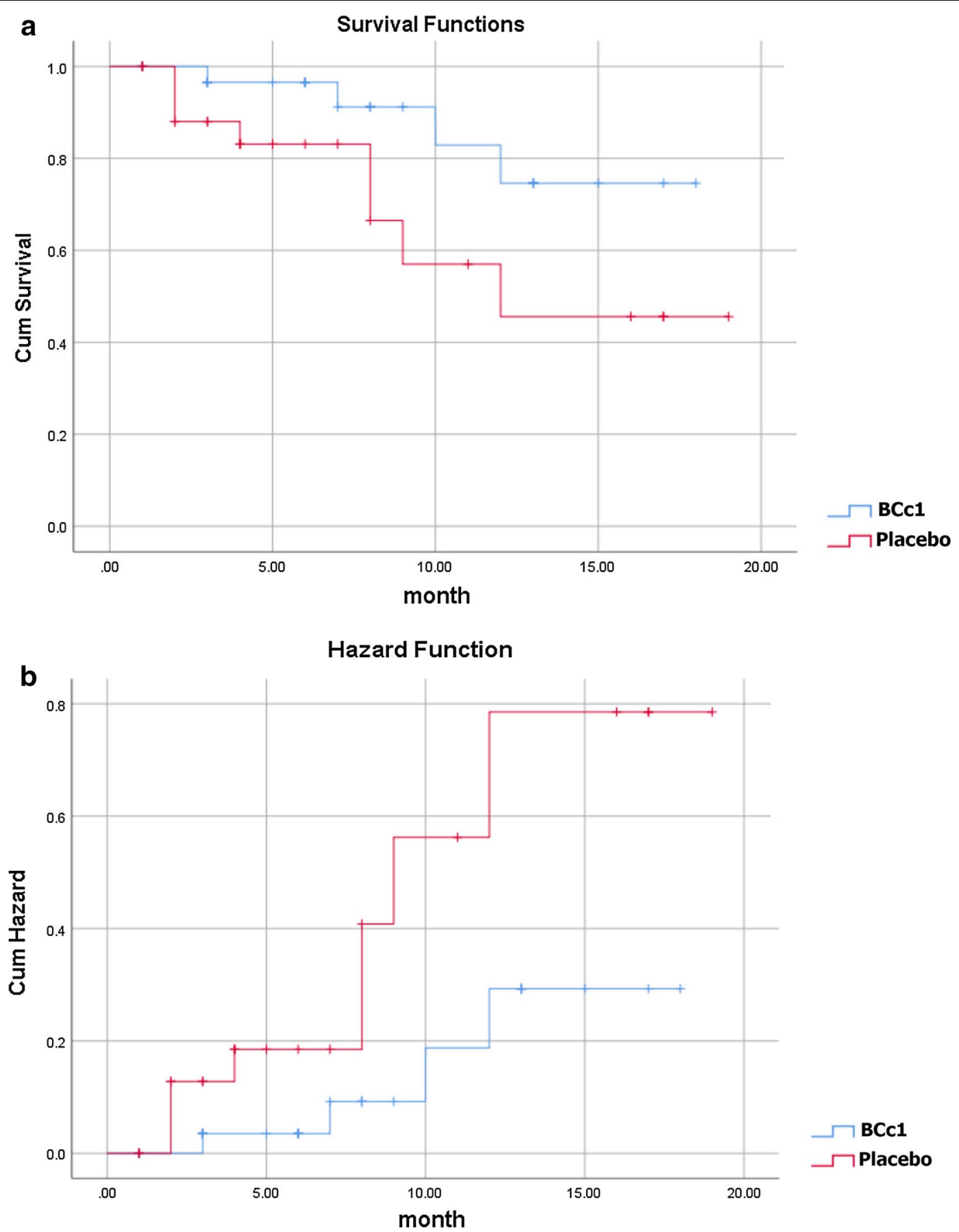

Fig. 4 a Kaplan-Meier diagram of survival. b Hazard function diagram in non-metastatic patients (Lifetime tables of hazard and survival for patients who received $\mathrm{BC} C 1$ nanomedicine show a higher survival and lower hazard than patients who received placebo)

equals 1.494 [95\% CI $0.42-5.32 ; \mathrm{p}=0.535]$. This value of HR indicates that in non-metastatic patients, the hazard of mortality for those who underwent chemotherapy is 1.494 times more than that of those who did not receive chemotherapy.

\section{Adverse effects}

The adverse effects including vomiting, nausea, neutropenia, and anorexia were not observed in patients in each treatment arm.

During the follow-up, no diarrhea was observed and 15 non-metastatic patients in $\mathrm{BCc} 1$ claimed an increase in 
Table 4 (A) Analysis of median of overall survival received interventions (BCc1nanomedicine or placebo) and chemotherapy simultaneously. (B) Death rate analysis received interventions (BCc1nanomedicine or placebo) and chemotherapy simultaneously

\begin{tabular}{|c|c|c|c|c|}
\hline \multirow{2}{*}{$\begin{array}{l}\text { Group } \\
\text { Total number }\end{array}$} & \multicolumn{2}{|l|}{ Metastatic } & \multicolumn{2}{|c|}{ Non- metastatic } \\
\hline & $B C c 1(n=14)$ & Placebo $(n=19)$ & $\mathrm{BCc} 1(n=12)$ & Placebo $(n=20)$ \\
\hline \multicolumn{5}{|l|}{ (A) Median of overall survival analysis } \\
\hline Median (days) & 302 & 107 & 482 & 265 \\
\hline Std. error & 133.23 & 55.09 & $-^{\mathrm{a}}$ & 27.769 \\
\hline Median 95\% Cl (lower) & 40.87 & 0 & $-^{\mathrm{a}}$ & 210.573 \\
\hline Median 95\% Cl (upper) & 563.13 & 214.98 & $-^{\mathrm{a}}$ & 319.427 \\
\hline $\begin{array}{l}\text { P-value for test of equality of survival } \\
\text { distributions }\end{array}$ & 0.306 & & 0.019 & \\
\hline $\begin{array}{l}\mathrm{HR}^{\mathrm{b}} \\
\text { (BCc1/Placebo) }\end{array}$ & 0.589 & & 0.019 & \\
\hline \multicolumn{5}{|l|}{ Stage (n) } \\
\hline । & 0 & 0 & 0 & 0 \\
\hline$\|$ & 0 & 0 & 0 & 3 \\
\hline III & 0 & 0 & 11 & 10 \\
\hline IIII & 14 & 19 & 0 & 0 \\
\hline \multicolumn{5}{|l|}{ (B) Death rate analysis } \\
\hline Death rate (\%) & 50 & 53 & 0 & 35 \\
\hline
\end{tabular}

Test of equality of survival distributions (for Bcc1 and placebo groups) assay with Log Rank (Mantel-Cox)

a No statistics are computed because all cases are censored

${ }^{\mathrm{b}}$ Univariate cox regression model

appetite and also there were no adverse events leading to death in placebo and $\mathrm{BCc} 1$ nanomedicine. The results of the whole blood, renal function, biochemical results, and hepatic function are shown at Table 7A-D respectively.

\section{Quality of life}

The global life quality of all patients was analyzed based on EORTC QLQ-C22 form including dysphagia scale, eating restrictions scale, anxiety scale, dry mouth, taste, and hair loss topics and in this form, lower scores indicated better global QOL.

Before randomization, all patients filled out EORTC QLQ-C22 form once, saved as "before form" in patients' documents. In patients who received the treatment, the form was filled out once more after 1.5 and 4 months for metastatic and non-metastatic patients, respectively, saved as "after form" in patients' documents.

As shown in Table 8, the mean difference (beforeafter) of global QOL improved (3.25, p >0.05) in metastatic patients who received $\mathrm{BCc} 1$, but it became worse $(-4.421, \mathrm{p}<0.05)$ in patients who received placebo. Likewise, as shown in Table 9, the mean difference (before-after) of global QOL improved (2.29, p>0.05) in non-metastatic patients who received $\mathrm{BCc} 1$, but it became worse $(-3, \mathrm{p}<0.05)$ in patients who received placebo.
In the same study, we did an analysis to investigate patients' QOL who received intervention (BCc1 or placebo) and chemotherapy simultaneously.

As shown in Table 10, the mean difference (beforeafter) of global QOL improved $(1.66, \mathrm{p}>0.05)$ in metastatic patients who received $\mathrm{BCc} 1$ and chemotherapy simultaneously, but it became worse $(-0.75, \mathrm{p}>0.05)$ in patients who received placebo and chemotherapy at the same time. Likewise, as shown in Table 11, the mean difference (before-after) of global QOL improved (0.714, $\mathrm{p}>0.05)$ in non-metastatic patients who received $\mathrm{BCc} 1$ and chemotherapy simultaneously, but it became worse $(-3.83, \mathrm{p}<0.05)$ in patients who received placebo and chemotherapy at the same time.

\section{Discussion}

Scientists all around the world have discovered a human genome map by mixing forces, which has had a dramatic effect on production of current medicine. It has also broadened the views leading to advancement of making new drugs and biological agents [30]. These new drugs, despite humane genomes' variability, must be capable to overcome various and special mechanisms causing diseases in every individual person.

Nanotechnology provides new approaches aiming for reduction of adverse effects of systemic delivery and 


\section{a}

Survival Functions

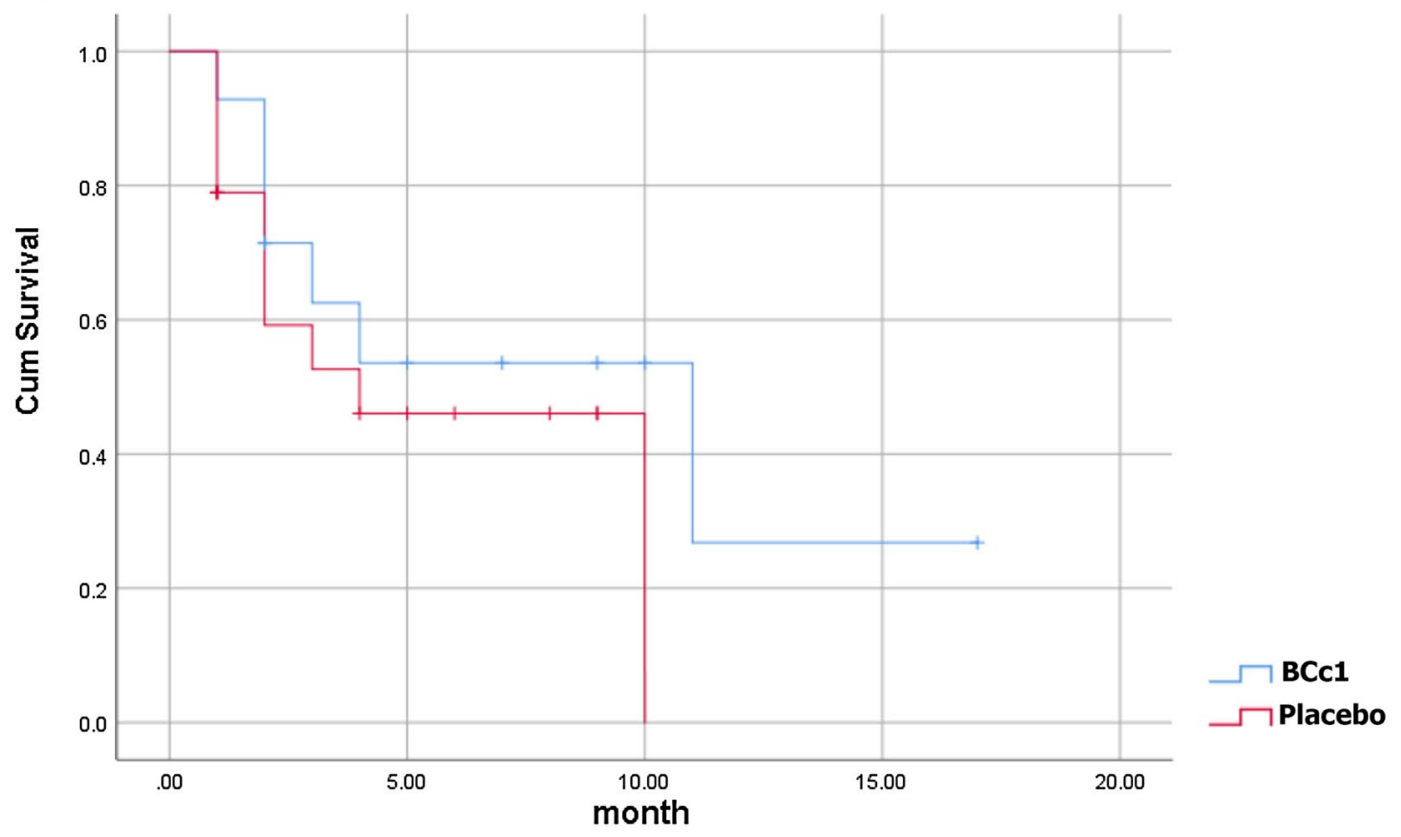

b

Hazard Function

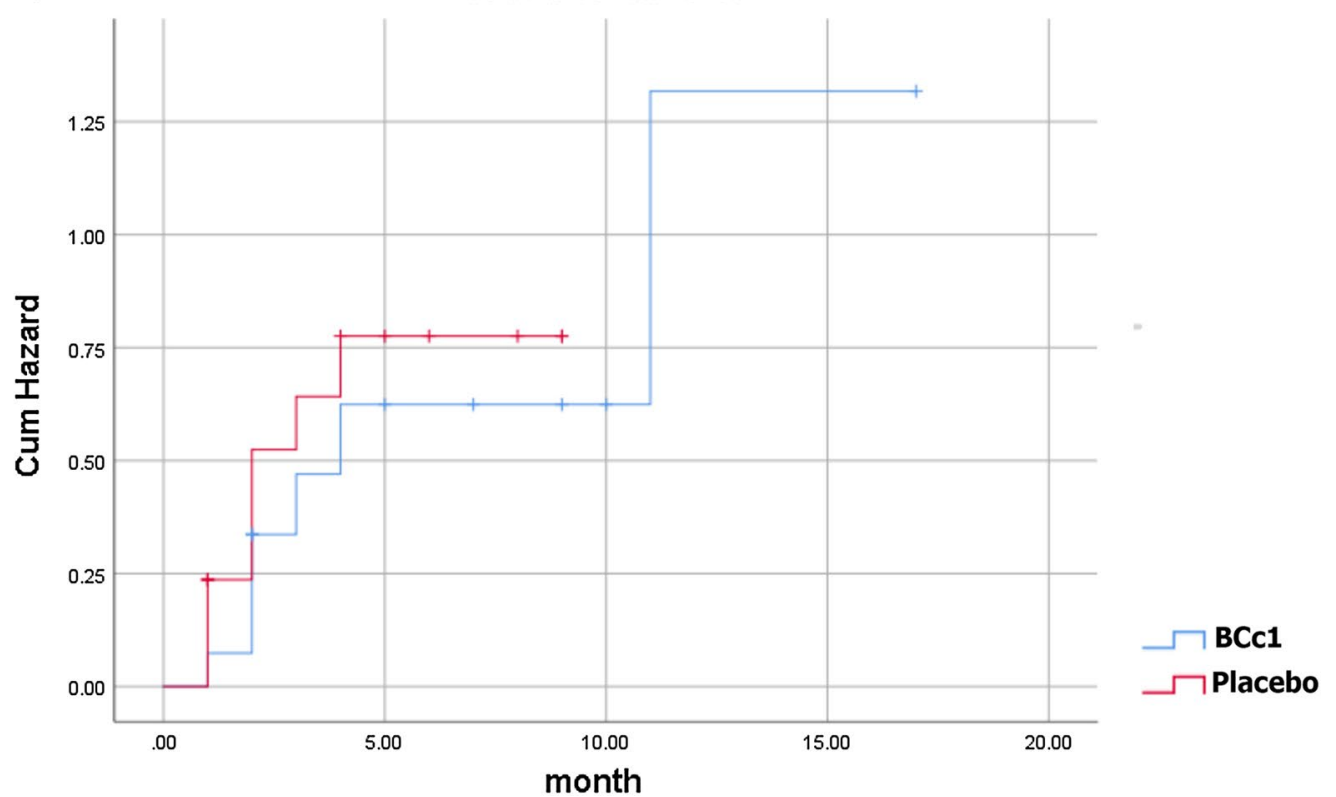

Fig. 5 a Kaplan-Meier diagram of survival. b Hazard function diagram in metastatic patients who received intervention (BCc1 nanomedicine or placebo capsule) and chemotherapy simultaneously

improvement of efficacy [14, 31]. Nowadays, due to the heavy side effects of normal tissues in cancer therapy, produced by a conventional therapeutic dose of antitumor drugs, scientists are inclined to use targeted nanodrug-delivery systems [30].
The results of an animal study, conducted by Chen LC, revealed that intravenous administration of (188) Reliposome could be beneficial and is considered a useful approach to delivering passive nano-targeted radio therapeutics in oncology applications [32]. 


\section{a \\ Survival Functions}
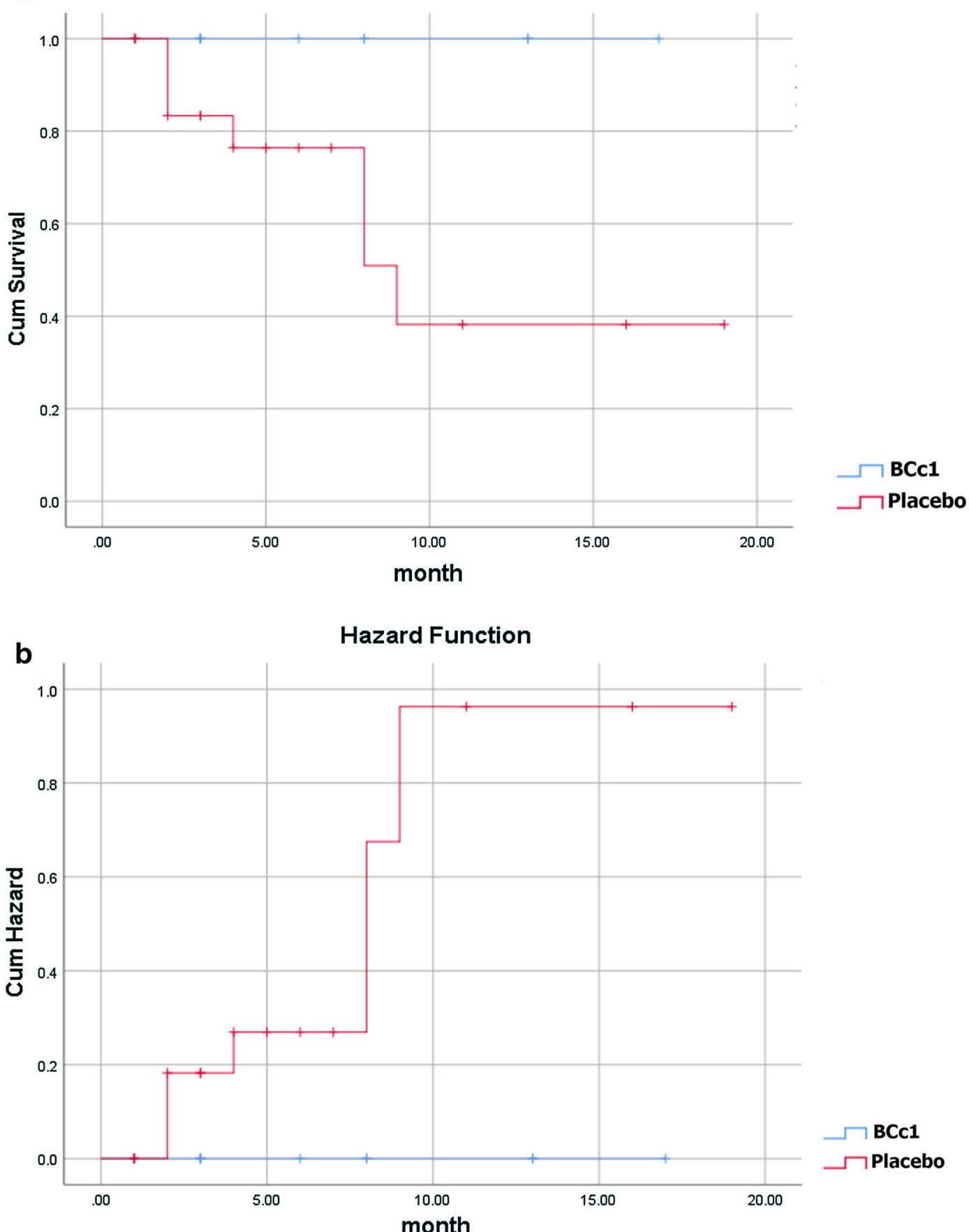

Fig. 6 a Kaplan-Meier diagram of survival. b Hazard function diagram in non-metastatic patients who received intervention (BCc1 nanomedicine or placebo capsule) and chemotherapy simultaneously

Doxil $^{\circledR}$ (liposomal doxorubicin) in 1995 and Onivyde $^{\circledR}$ (liposomal irinotecan) in 2015 were the first generation of nanomedicine receiving clinical approval in the last two decades [33, 34].

The results of a meta-analysis disclosed that liposomal doxorubicin-based chemotherapy is associated with a significant reduction in the risk of cardio toxicity [35]. The FDA recently approved that nano liposomal irinotecan combined with fluorouracil/folinic acid can significantly prolong progression of free survival and OS in comparison to fluorouracil/folinic acid [36]. 
Table 5 Median of overall survival analysis of patients who only received intervention: (A) BCc1 nanomedicine or Placebo without chemotherapy. (B) Death percentage analysis of patients who only received intervention: BCc1 nanomedicine or Placebo without chemotherapy

\begin{tabular}{|c|c|c|c|c|}
\hline \multirow{2}{*}{$\begin{array}{l}\text { Group } \\
\text { Total number }\end{array}$} & \multicolumn{2}{|l|}{ Metastatic } & \multicolumn{2}{|c|}{ Non-metastatic } \\
\hline & $\mathrm{BCc} 1(\mathrm{n}=19)$ & Placebo $(n=11)$ & $\mathrm{BCc} 1(n=18)$ & Placebo $(n=10)$ \\
\hline \multicolumn{5}{|l|}{ (A) Median of overall survival analysis } \\
\hline Median (days) & 174 & 52 & 442 & 454 \\
\hline Std. error & 46.75 & 46.64 & 41.43 & 44.635 \\
\hline Median 95\% Cl (lower) & 118.40 & 0 & 361 & 366 \\
\hline Median 95\% Cl (upper) & 229.59 & 113.69 & 523 & 541 \\
\hline $\begin{array}{l}\text { P-value for test of equality of survival } \\
\text { distributions }\end{array}$ & 0.042 & & 0.053 & \\
\hline $\begin{array}{l}\text { HR } \\
\text { (BCc1/Placebo) }\end{array}$ & 0.500 & & 0.324 & \\
\hline \multicolumn{5}{|l|}{ Stage (n) } \\
\hline I & 0 & 0 & 3 & 1 \\
\hline$\|$ & 0 & 0 & 3 & 4 \\
\hline III & 0 & 0 & 8 & 3 \\
\hline IIII & 19 & 11 & 0 & 0 \\
\hline \multicolumn{5}{|c|}{ (B) Death rate analysis median of overall survival analysis } \\
\hline Death rate (\%) & 49 & 63 & 13 & 30 \\
\hline
\end{tabular}

Test of equality of survival distributions for (Bcc1 an0d placebo groups) assay with Log Rank (Mantel-Cox)

The nanochelating technology, patented [15] as a new approach, is proving to have a significant role in treatment of different diseases by synthesizing different nanostructures that possess effective properties. The very same nanostructures have some physical and chemical properties such as saturation solubility, dissolution rate, crystal form, particle surface hydrophobicity, and hydrophobicity physical response [37].

Nano particles that are produced by nanochelating technology are biodegradable and/or biocompatible and are synthesized using controlled self-assembly method [38]; as a result, the nanostructures produced by this method are completely unique because it is so powerful in chemistry protocols and can synthesize organic and inorganic building blocks into unprecedented structures and patterns [10].

In the previous study, $\mathrm{BCc} 1$ nanomedicine was designed based on the nanochelating technology for cancer treatment experimented in vitro and vivo studies and the results showed that $\mathrm{BCc} 1$ has high potentials to induce therapeutic behavior [8].

According to some data in 2013-2015, almost $0.8 \%$ of people will be diagnosed with stomach cancer at some point in their lifetime, so we investigated the effects of this nanomedicine in patients with gastric cancer [2].

$\mathrm{BCc} 1$ is the only nanomedicine that is designed and used in the domain of human cancers based on selfassembly method $[38,39]$. Even in the most interiors of cancer stem cells (CSC) niches, nanomedicines are capable of delivering drug molecules and transcending the limitations of conventional free drug delivery approaches [40].

Most drug-resistant cancer cells and CSCs show high levels of CD44 receptor which binds hyaluronate [41]. CD44 is potentially able to be targeted for the treatment of drug-resistant tumors and CSC [42]. The results of the previous study revealed that $\mathrm{BCc} 1$ can reduce $\mathrm{CD} 44$ expression in cancer cell line; as a result, we can assume that $\mathrm{BCc} 1$ is able to affect CSCs [8].

One of the properties of $\mathrm{BCc} 1$ is chelating iron which can arrest G1/S phase and cause the death of cancer cells using apoptosis mechanism, while no apoptosis was observed in normal cells with an identical BCc1 dose [8]. In the present study, $\mathrm{BCc} 1$ nanomedicine does not have any side effects like nausea, diarrhea, vomiting, and anomie in patients with gastric cancer.

OS could be considered the primary endpoint of cancer treatment in the present and future [29]. BCc1 has already proved that it is able to increase the survival rates and decrease metastasis in mice bearing adenoma carcinoma. In the present study, in order to investigate the effect of $\mathrm{BCc} 1$ nanomedicine on OS at a clinical trial (randomized and placebo controlled), some patients with metastatic and none-metastatic gastric cancer were analyzed after taking $\mathrm{BCc} 1$ nanomedicine. It was shown that $\mathrm{BCc} 1$ nanomedicine can increase median OS compared 

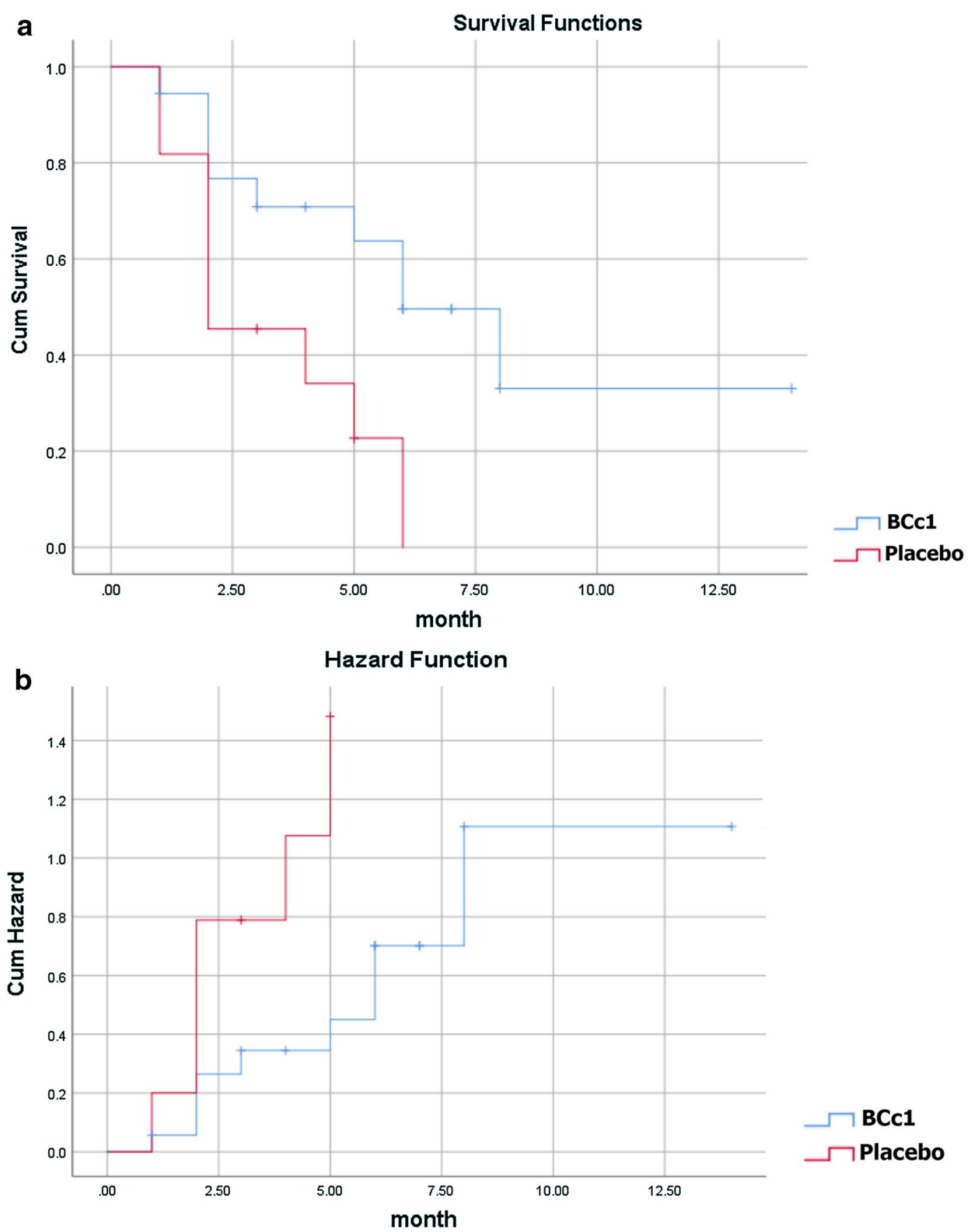

Fig. 7 a Kaplan-Meier diagram of survival. b Hazard function diagram in metastatic patients who only received interventions (BCc1 nanomedicine or placebo) without undergoing chemotherapy

to placebo, both in metastatic and none-metastatic gastric cancer patients.

As shown in Kaplan-Meier diagram for metastatic patients, half of the deaths in patients who took placebo capsules occurred in the first 30 days of the study, but half of the deaths in patients who took BCc1 nanomedicine occurred in the first 50 days (Fig. 3). In addition, as shown in Kaplan-Meier diagram for nonmetastatic patients, half of the deaths in patients who took placebo capsules occurred in the first 3 months of the study, but half of the deaths in patients who took 


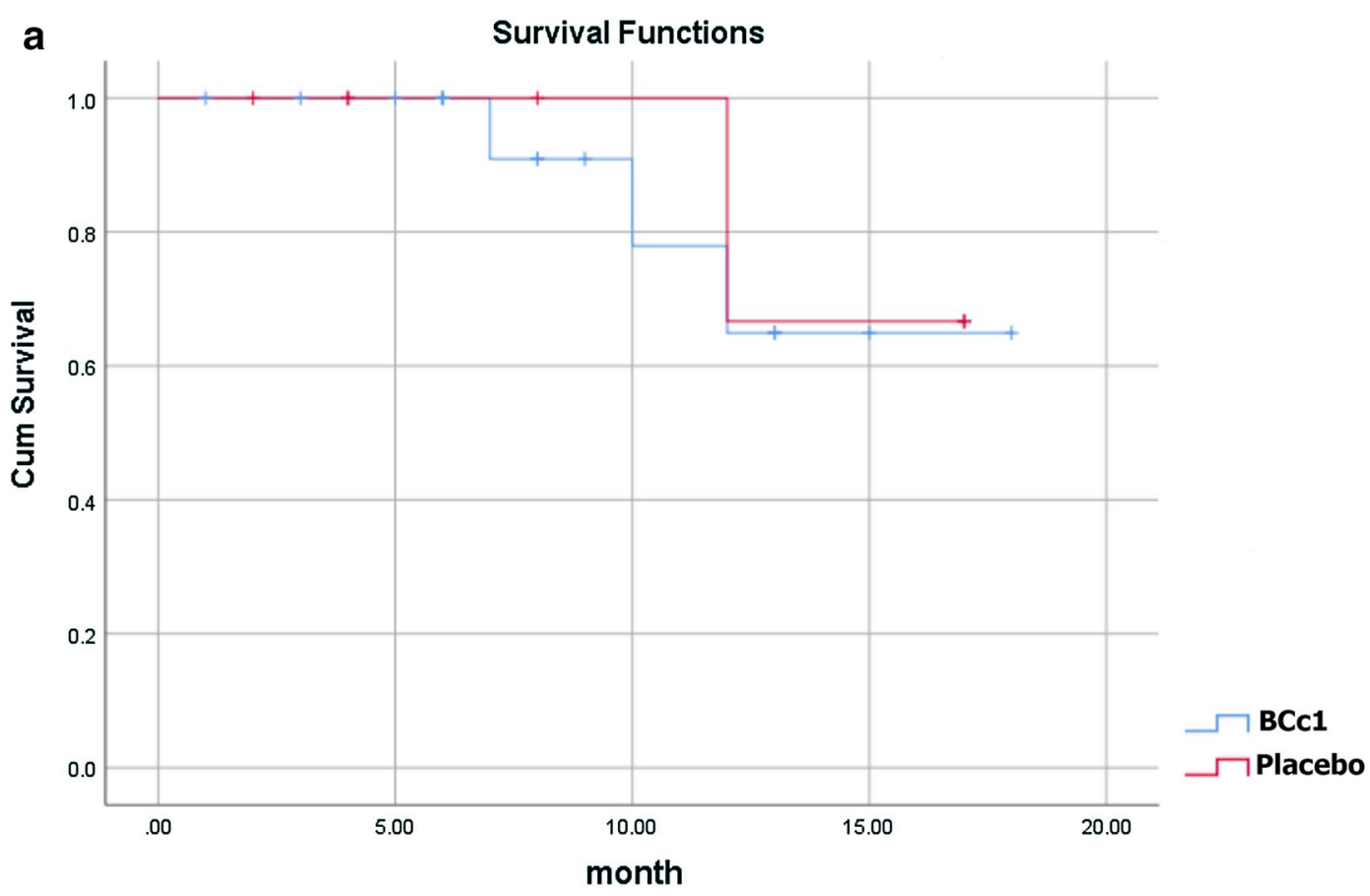

b

Hazard Function

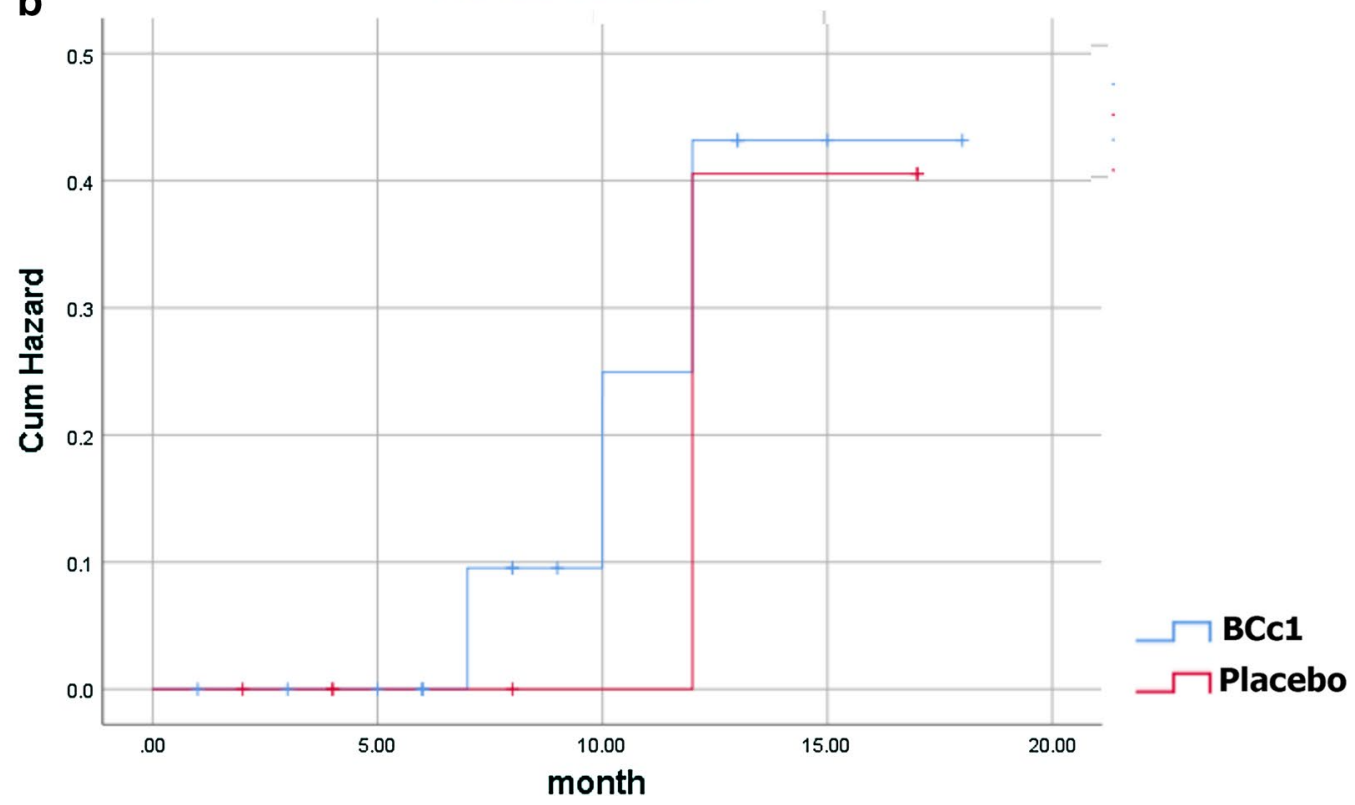

Fig. 8 a Kaplan-Meier diagram of survival. b Hazard function diagram in non-metastatic patients who only received interventions (BCc1 nanomedicine or placebo) without undergoing chemotherapy

BCc1 nanomedicine occurred in the first 6 months (Fig. 4).

In conclusion, in both metastatic and non-metastatic patients, those who took $\mathrm{BCc} 1$ nanomedicine lived longer than those who took placebo.
As confirmed by ethics committee, no treatment was removed from the study and a number of patients received chemotherapy simultaneously both in $\mathrm{BCc} 1$ nanomedicine and placebo groups. To investigate the simultaneous effect of chemotherapy and intervention (BCc1 or placebo) on OS, an analysis was conducted on 
Table 6 Cox multivariate regression model. (A) metastatic gastric cancer patients. (B) Non-metastatic gastric cancer patients

\begin{tabular}{|c|c|c|c|c|c|c|}
\hline \multicolumn{7}{|l|}{ Variables in the equation } \\
\hline & \multirow[t]{2}{*}{ B } & \multirow[t]{2}{*}{ df } & \multirow[t]{2}{*}{ Sig. } & \multirow[t]{2}{*}{$\operatorname{Exp}(B)$} & \multicolumn{2}{|c|}{$95.0 \% \mathrm{Cl}$} \\
\hline & & & & & Lower & Upper \\
\hline \multicolumn{7}{|c|}{ (A) Cox multivariate regression model for metastatic gastric cancer } \\
\hline $\mathrm{BCC} 1$ nanomedicine indicator & -0.743 & 1 & 0.039 & 0.476 & 0.235 & 0.962 \\
\hline Chemotherapy indicator & -0.306 & 1 & 0.388 & 0.737 & 0.368 & 1.474 \\
\hline \multicolumn{7}{|c|}{ (B) Cox multivariate regression model for non-metastatic gastric cancer } \\
\hline $\mathrm{BC} 1$ nanomedicine indicator & -1.316 & 1 & 0.057 & 0.268 & 0.069 & 1.042 \\
\hline Chemotherapy-indicator & 0.401 & 1 & 0.535 & 1.494 & 0.420 & 5.315 \\
\hline
\end{tabular}

Table 7 Whole blood (A), renal function (B), biochemical results (C) and hepatic function (D) of the patients who took BCC1 nanomedicine revealed that none of the patients suffered deficiency

\begin{tabular}{|c|c|c|}
\hline Index & Unit & Amount \\
\hline \multicolumn{3}{|l|}{ (A) Whole blood function } \\
\hline WBC & $\times 1000 / \mathrm{mm}^{3}$ & $5.1 \pm 1.3$ \\
\hline $\mathrm{RBC}$ & $\mathrm{Mill} / \mathrm{mm}^{3}$ & $4.4 \pm 0.6$ \\
\hline $\mathrm{HGB}$ & $\mathrm{g} / \mathrm{dl}$ & $12.5 \pm 1.8$ \\
\hline $\mathrm{HCT}$ & $\%$ & $40.1 \pm 4.5$ \\
\hline MCV & $\mathrm{Fl}$ & $88.4 \pm 10.2$ \\
\hline $\mathrm{MCH}$ & $\mathrm{pg}$ & $28.8 \pm 4.3$ \\
\hline $\mathrm{MCHC}$ & $\mathrm{g} / \mathrm{dl}$ & $32.9 \pm 1.8$ \\
\hline Platelet & $\times 1000 / \mathrm{mm}^{3}$ & $195 \pm 27$ \\
\hline RDW & & $43 \pm 21.1$ \\
\hline PDW & $\mathrm{Fl}$ & $13.3 \pm 0.8$ \\
\hline MPV & $\mathrm{Fl}$ & $10 \pm 1.6$ \\
\hline \multicolumn{3}{|l|}{ (B) Renal function } \\
\hline Urea & $\mathrm{mg} / \mathrm{dl}$ & $30.4 \pm 13.6$ \\
\hline Creatinine & $\mathrm{mg} / \mathrm{dl}$ & $1.0 \pm 0.1$ \\
\hline \multicolumn{3}{|l|}{ (C) Biochemical function } \\
\hline Iron & $\mu \mathrm{g} / \mathrm{dl}$ & $56 \pm 15$ \\
\hline $\mathrm{TIBC}$ & $\mu \mathrm{g} / \mathrm{dl}$ & $314 \pm 30$ \\
\hline UIBC & $\mu \mathrm{g} / \mathrm{dl}$ & $258 \pm 10$ \\
\hline Ferritin & $\mathrm{ng} / \mathrm{dl}$ & $250 \pm 80$ \\
\hline Sodium & $\mathrm{mmol} / \mathrm{l}$ & $139 \pm 7$ \\
\hline Potassium & $\mathrm{mmol} / \mathrm{l}$ & $4.1 \pm 0.7$ \\
\hline Chloride & $\mathrm{mmol} / \mathrm{l}$ & $105 \pm 10$ \\
\hline \multicolumn{3}{|l|}{ (D) Hepatic function } \\
\hline Triglycerides & $\mathrm{mg} / \mathrm{dl}$ & $102 \pm 48$ \\
\hline Total cholesterol & $\mathrm{mg} / \mathrm{dl}$ & $183 \pm 22$ \\
\hline AST (SGOT) & $\mathrm{U} / \mathrm{I}$ & $19.1 \pm 5.1$ \\
\hline ALT (SGPT) & $\mathrm{U} / \mathrm{I}$ & $14.3 \pm 4.3$ \\
\hline Alkaline phosphatase & $|\mathrm{U} /|$ & $286.6 \pm 95$ \\
\hline Bilirubin (total) & $\mathrm{mg} / \mathrm{dl}$ & $0.725 \pm 0.09$ \\
\hline Bilirubin (direct) & $\mathrm{mg} / \mathrm{dl}$ & $0.2 \pm 0.1$ \\
\hline
\end{tabular}

the data revealing that in patients with metastatic gastric cancer, the median OS was significantly longer, in patients who simultaneously received chemotherapy and $\mathrm{BC} 1$ than those who received chemotherapy and placebo at the same time. The analysis also showed that in patients with none-metastatic gastric cancer, the median OS was longer, although not significantly, in patients who simultaneously received chemotherapy and BCc1 nanomedicine than those who simultaneously received chemotherapy and placebo.

These results prove the hypothesis that there is synergism effect between mechanisms of $\mathrm{BCc} 1$ nanomedicine and conventional treatments like chemotherapy.

To investigate the effect of $\mathrm{BCc} 1$ nanomedicine on OS, an analysis was conducted on the data revealing that in patients with metastatic and non-metastatic gastric cancer, those who only received $\mathrm{BCc} 1$ without chemotherapy lived longer, which shows the therapeutic effect of BCc1 nanomedicine. This finding can be the subject of future clinical trials with a larger number of patients.

QOL measures provide helpful information of global well-being and functional status of patients, which is why QOL is critical for complete evaluation of new treatments for patients with cancer $[29,43]$.

The study findings revealed that the $\mathrm{BCc} 1$ group enjoyed more improvement, regarding global QOL, in comparison with the placebo group in both metastatic and none-metastatic groups.

As the results show, the similar QOL and OS improvement pattern proves the positive effect of $\mathrm{BCc} 1$ nanomedicine on these patients.

A potential limitation of the trial was the point that because the patients suffered gastric cancer at metastatic stage, taking 3 capsules in each serving was hard for them; therefore, in the future, it is recommended to use $\mathrm{BCc} 1$ nanomedicine for gastric cancer patients (end stage and metastatic) through other application methods. 
Table 8 (A) Quality of life of metastatic gastric cancer patients, (B) Median difference before-after of quality of Life

\begin{tabular}{|c|c|c|c|c|c|c|c|c|}
\hline & $\begin{array}{l}\text { Mean } \\
\text { (before) }\end{array}$ & $\begin{array}{l}\text { Std. } \\
\text { deviation }\end{array}$ & $\begin{array}{l}\text { Std. } \\
\text { error }\end{array}$ & P-value & $\begin{array}{l}\text { Mean } \\
\text { (after) }\end{array}$ & $\begin{array}{l}\text { Std. } \\
\text { deviation }\end{array}$ & $\begin{array}{l}\text { Std. } \\
\text { error }\end{array}$ & P-value \\
\hline \multicolumn{9}{|c|}{ (A) Quality of life in patients with metastatic gastric cancer } \\
\hline $\begin{array}{l}\text { Global quality } \\
\text { (BCc1 nanomedicine) }\end{array}$ & 48.88 & 13.614 & 2.779 & 0.118 & 45.63 & 11.009 & 2.247 & 0.200 \\
\hline \multirow{2}{*}{$\begin{array}{l}\text { Global quality } \\
\text { (Placebo) }\end{array}$} & 47.16 & 13.280 & 3.047 & 0.200 & 51.58 & 12.384 & 2.841 & 0.200 \\
\hline & \multicolumn{2}{|l|}{ Mean* } & \multicolumn{2}{|c|}{ Std. deviation } & \multicolumn{3}{|c|}{ Std. error mean } & P-value \\
\hline \multicolumn{9}{|c|}{ (B) Median difference (before-after) of quality of life } \\
\hline Quality of BCc1 (before-after) & \multicolumn{2}{|l|}{3.250} & \multicolumn{2}{|l|}{8.975} & \multicolumn{2}{|c|}{1.832} & & 0.089 \\
\hline $\begin{array}{l}\text { Quality of Placebo (before- } \\
\text { after) }\end{array}$ & \multicolumn{2}{|l|}{-4.421} & \multicolumn{2}{|l|}{6.947} & \multicolumn{2}{|c|}{1.594} & & 0.013 \\
\hline
\end{tabular}

* Higher score show better global quality of life

Table 9 (A) Quality of life of non-metastatic gastric cancer patients, (B) Median difference before-after of quality of Life

\begin{tabular}{|c|c|c|c|c|c|c|c|c|}
\hline & $\begin{array}{l}\text { Mean } \\
\text { (before) }\end{array}$ & $\begin{array}{l}\text { Std. } \\
\text { deviation }\end{array}$ & $\begin{array}{l}\text { Std. } \\
\text { error mean }\end{array}$ & P-value & $\begin{array}{l}\text { Mean } \\
\text { (after) }\end{array}$ & $\begin{array}{l}\text { Std. } \\
\text { deviation }\end{array}$ & $\begin{array}{l}\text { Std. } \\
\text { deviation }\end{array}$ & P-value \\
\hline \multicolumn{9}{|c|}{ (A) Quality of life in patients with non-metastatic gastric cancer } \\
\hline $\begin{array}{l}\text { Global quality } \\
\text { (BCc1 nanomedicine) }\end{array}$ & 40.75 & 9.013 & 1.840 & 0.118 & 38.46 & 9.532 & 9.013 & 0.200 \\
\hline \multirow{2}{*}{$\begin{array}{l}\text { Global quality } \\
\text { (Placebo) }\end{array}$} & 47.11 & 12.009 & 2.831 & 0.200 & 50.11 & 14.046 & 12.009 & 0.200 \\
\hline & \multicolumn{2}{|c|}{ Mean* } & \multicolumn{2}{|c|}{ Std. deviation } & \multicolumn{3}{|c|}{ Std. error mean } & P-value \\
\hline \multicolumn{9}{|c|}{ (B) Median difference (before-after) of quality of life } \\
\hline $\begin{array}{l}\text { Quality of BCc1 } \\
\text { (before-after) }\end{array}$ & \multicolumn{2}{|c|}{2.29} & \multicolumn{2}{|c|}{5.497} & \multicolumn{2}{|r|}{1.122} & & 0.053 \\
\hline $\begin{array}{l}\text { Quality of Placebo } \\
\text { (before-after) }\end{array}$ & \multicolumn{2}{|c|}{-3} & \multicolumn{2}{|c|}{12.009} & \multicolumn{2}{|r|}{2.831} & & 0.038 \\
\hline
\end{tabular}

* Higher score show better global quality of life

Table 10 (A) Quality of life of metastatic gastric cancer, (patient's received intervention and chemotherapy simultaneously). (B) Median difference before -after of Quality of Life

\begin{tabular}{|c|c|c|c|c|c|c|c|c|}
\hline & $\begin{array}{l}\text { Mean } \\
\text { (before) }\end{array}$ & $\begin{array}{l}\text { Std. } \\
\text { deviation }\end{array}$ & $\begin{array}{l}\text { Std. } \\
\text { error }\end{array}$ & P-value & $\begin{array}{l}\text { Mean } \\
\text { (after) }\end{array}$ & $\begin{array}{l}\text { Std. } \\
\text { deviation }\end{array}$ & $\begin{array}{l}\text { Std. } \\
\text { error }\end{array}$ & P-value \\
\hline \multicolumn{9}{|c|}{ (A) Quality of life in patients with metastatic gastric cancer } \\
\hline $\begin{array}{l}\text { Global quality } \\
\text { (BCc1 nanomedicine) }\end{array}$ & 45.89 & 12.869 & 4.290 & 0.200 & 44.22 & 10.721 & 3.574 & 0.200 \\
\hline \multirow{2}{*}{$\begin{array}{l}\text { Global quality } \\
\text { (Placebo) }\end{array}$} & 49.08 & 13.318 & 3.844 & 0.200 & 49.83 & 13.265 & 3.829 & 0.200 \\
\hline & \multicolumn{2}{|l|}{ Mean* } & \multicolumn{2}{|c|}{ Std. deviation } & \multicolumn{3}{|c|}{ Std. error mean } & P-value \\
\hline \multicolumn{9}{|c|}{ (B) Median difference (before-after) of quality of life } \\
\hline Quality of BCc1 (before-after) & \multicolumn{2}{|c|}{$\quad 1.667$} & \multicolumn{2}{|l|}{7.053} & \multicolumn{2}{|c|}{2.351} & & 0.499 \\
\hline $\begin{array}{l}\text { Quality of Placebo (before- } \\
\text { after) }\end{array}$ & \multicolumn{2}{|l|}{-0.750} & \multicolumn{2}{|l|}{2.958} & \multicolumn{2}{|c|}{0.854} & & 0.399 \\
\hline
\end{tabular}

* Higher score show better global quality of life 
Table 11 (A) Quality of life of non- metastatic gastric cancer, (patient's received intervention and chemotherapy simultaneously). (B) Median difference before-after of quality of life

\begin{tabular}{|c|c|c|c|c|c|c|c|c|}
\hline & $\begin{array}{l}\text { Mean } \\
\text { (before) }\end{array}$ & $\begin{array}{l}\text { Std. } \\
\text { deviation }\end{array}$ & $\begin{array}{l}\text { Std. } \\
\text { error }\end{array}$ & P-value & $\begin{array}{l}\text { Mean } \\
\text { (after) }\end{array}$ & $\begin{array}{l}\text { Std. } \\
\text { deviation }\end{array}$ & $\begin{array}{l}\text { Std. } \\
\text { deviation }\end{array}$ & P-value \\
\hline \multicolumn{9}{|c|}{ (A) Quality of life in patients with non-metastatic gastric cancer } \\
\hline $\begin{array}{l}\text { Global quality } \\
\text { (BCc1 nanomedicine) }\end{array}$ & 38.29 & 10.045 & 3.797 & 0.200 & 37.57 & 11.267 & 4.259 & 0.200 \\
\hline \multirow{2}{*}{$\begin{array}{l}\text { Global quality } \\
\text { (Placebo) }\end{array}$} & 50.75 & 10.931 & 3.155 & 0.200 & 54.58 & 12.176 & 3.515 & 0.200 \\
\hline & \multicolumn{2}{|l|}{ Mean* } & \multicolumn{2}{|c|}{ Std. deviation } & \multicolumn{3}{|c|}{ Std. error mean } & P-value \\
\hline \multicolumn{9}{|c|}{ (B) Median difference (before-after) of quality of life } \\
\hline Quality of BCc1 (before-after) & \multicolumn{2}{|l|}{0.714} & \multicolumn{2}{|l|}{6.184} & \multicolumn{2}{|r|}{2.337} & & 0.077 \\
\hline $\begin{array}{l}\text { Quality of Placebo (before- } \\
\text { after) }\end{array}$ & \multicolumn{2}{|l|}{-3.833} & \multicolumn{2}{|c|}{5.441} & \multicolumn{2}{|r|}{1.571} & & 0.033 \\
\hline
\end{tabular}

* Higher score show better global quality of life

\section{Conclusion}

The findings of the present study reveals that BCc1 nanomedicine could have a positive effect on QOL and OS without any side effects in patients with cancer in addition to its therapeutic effects as a medicine alone and also BCc1 nanomedicine could have synergism effects when used with chemotherapy drugs at the same time. Complementary studies in the future would hopefully confirm the effectiveness of our new nanomedicine for cancer treatment.

\section{Additional file}

Additional file 1. $\mathrm{BCC} 1$ nanomedicine toxicity report (Oral

$\mathrm{LD} 50=1776.59 \mathrm{mg} / \mathrm{kg}$ ).

\section{Abbreviations}

FDA: Food and Drug Administration; IP: intraperitoneal; LD50: lethal dose; OS: overall survival; QOL: quality of life; EUS: endoscopic ultrasound; CT scan: computed tomography scan; PET scan: positron emission tomography scan; AJCC: American Joint Committee on Cancer staging system guideline; NOAEL: No Observed Adverse Effect Level; FIH: first-in-human; API: active pharmaceutical ingredient; HRs: hazard ratios; Cl: confidence interval; CSC: cancer stem cells.

\section{Authors' contributions}

$\mathrm{MH}$ performed most of the experiments and data acquisition and also wrote the manuscript. SK carried out the synthesis of the BCC1 nanomedicine. SN and $M K H$ performed the statistical analysis. VK, BG, HF, MR, AJ, SS, MA, AZ, and $\mathrm{HM}$ collected the data and selected the patients. MHN contributed to the conception and design of the $\mathrm{BCC} 1$ nanomedicine. MEA designed the study. All authors read and approved the final manuscript.

\section{Author details}

'Cancer Research Centre, Shahid Beheshti University of Medical Sciences, Tehran, Iran. ${ }^{2}$ Department of Research and Development, Sodour Ahrar Shargh Company, Tehran, Iran. ${ }^{3}$ Department of Statistics, Faculty of Sciences, University of Qom, Qom, Iran. ${ }^{4}$ Firouzgar Hospital, Iran University of Medical Sciences, Tehran, Iran. ${ }^{5}$ Naft Company Hospital, Tehran, Iran. ${ }^{6}$ Shahid FayazBakhsh Hospital, Tehran, Iran. ${ }^{7}$ Department of Medical Oncology and Hematology, Tehran Medical Sciences Branch, Islamic Azad University, Tehran, Iran.
${ }^{8}$ Department of Medicinal and Pharmaceutical Chemistry, Shahid Beheshti University of Medical Sciences, Tehran, Iran.

\section{Acknowledgements}

The Support for this work was provided by the Department of Research and Development at Sodour Ahrar Shargh Company and Cancer Research Centre at Shahid Beheshti University of Medical Sciences and also we wish to acknowledge the contribution of Dr Seyed Mahdi Mousavi, Dr Seyed Hamid Mostafavi and Dr Abdolkarimi (CEO and board of director's member at Tehran Darou Pharmaceutical Co., Tehran, Iran) to this study.

\section{Competing interests}

The authors declare that they have no competing interests.

\section{Availability of data materials}

The datasets generated during the current study are available from the corresponding author on reasonable request.

\section{Consent for publication}

Not applicable.

\section{Ethics approval and consent to participate}

This trial is registered with Iranian Registry of Clinical Trials; Reg. No. IRCT2017101935423N1. It has also received the ethic approval of Shahid Beheshti University of Medical Sciences, Tehran, Iran; Reg. No. IR.SBMU. REC.1396.2.

Funding

Not applicable.

\section{Publisher's Note}

Springer Nature remains neutral with regard to jurisdictional claims in published maps and institutional affiliations.

Received: 10 September 2018 Accepted: 3 April 2019

Published online: 10 April 2019

\section{References}

1. Cancer - World Health Organization. http://www.who.int/news-room/ fact-sheets/detail/cancer.

2. American Cancer Society. https://www.cancer.org/cancer/acs-medic al-content-and-news-staff.html).

3. GuY, et al. LncRNAs: emerging biomarkers in gastric cancer. Future Oncol. 2015;11(17):2427-41. 
4. Xu W, Yang Z, Lu N. Molecular targeted therapy for the treatment of gastric cancer. J Exp Clin Cancer Res. 2016:35:1.

5. https://seer.cancer.gov/statfacts/html/stomach.html.

6. Hamashima C. Current issues and future perspectives of gastric cancer screening. World J Gastroenterol. 2014;20(38):13767-74.

7. Veisani Y, Delpisheh A. Survival rate of gastric cancer in Iran; a systematic review and meta-analysis. Gastroenterol Hepatol Bed Bench. 2016;9(2):78-86.

8. Kalanaky S, et al. BCc1, the novel antineoplastic nanocomplex, showed potent anticancer effects in vitro and in vivo. Drug Des Devel Ther. 2016;10:59-70

9. Zhao CY, et al. Nanotechnology for cancer therapy based on chemotherapy. Molecules. 2018;23(4):236.

10. Perez-Herrero E, Fernandez-Medarde A. Advanced targeted therapies in cancer: drug nanocarriers, the future of chemotherapy. Eur J Pharm Biopharm. 2015;93:52-79.

11. Poonia M, et al. Nanotechnology in oral cancer: a comprehensive review. J Oral Maxillofac Pathol. 2017;21(3):407-14.

12. Tran S, et al. Cancer nanomedicine: a review of recent success in drug delivery. Clin Transl Med. 2017:6(1):44

13. Kydd J, et al. Targeting strategies for the combination treatment of cancer using drug delivery systems. Pharmaceutics. 2017;9(4):46.

14. He C, et al. Nanomedicine for combination therapy of cancer. EBioMedicine. 2015;2(5):366-7.

15. Nazaran MH. Chelate compounds. Google Patents US8288587B2; 2012.

16. Seyfori $\mathrm{H}$, et al. Growth performance, mineral digestibility, and blood characteristics of ostriches receiving drinking water supplemented with varying levels of chelated trace mineral complex. Biol Trace Elem Res. 2018;183(1):147-55.

17. Hafizi M, et al. Nanochelating based nanocomplex, GFc7, improves quality and quantity of human mesenchymal stem cells during in vitro expansion. Stem Cell Res Ther. 2015;6:226.

18. Fakharzadeh S, et al. The therapeutic effects of MSc1 nanocomplex, synthesized by nanochelating technology, on experimental autoimmune encephalomyelitic C57/BL6 mice. Int J Nanomed. 2014;9:3841-53.

19. Zhao MX, Zhu BJ. The research and applications of quantum dots as nano-carriers for targeted drug delivery and cancer therapy. Nanoscale Res Lett. 2016;11(1):207.

20. Matsuoka T, Yashiro M. Biomarkers of gastric cancer: current topics and future perspective. World J Gastroenterol. 2018;24(26):2818-32.

21. Cheon C, et al. Sipjeondaebo-tang in patients with breast cancer with fatigue: a protocol for a pilot, randomised, double-blind, placebocontrolled, cross-over trial. BMJ Open. 2018;8(7):e021242.

22. American Joint Committee on Cancer (AJCC) staging system guideline, 8th Edn, 2018. http://cancerstaging.org/references-tools/deskrefere nces/Pages/default.aspx.

23. Sadighi $\mathrm{S}$, et al. Quality of life in patients with gastric cancer: translation and psychometric evaluation of the Iranian version of EORTC QLQ-STO22. BMC Cancer. 2009;9:305.

24. Center for Drug Evaluation and Research. Guidance for industry estimating the maximum safe starting dose in initial clinical trials for therapeutics in adult healthy volunteers. 2005. https://www.federalregister.gov/docum ents/2005/07/22/05-14456/guidance-for-industryon-estimating-themaximum-safe-starting-dose-in-initial-clinical-trials.

25. Breslow NE. Introduction to Kaplan and Meier (1958) Nonparametric estimation from incomplete observations. In: Breakthroughs in Statistics. 1992. https://doi.org/10.1007/978-1-4612-4380-9_24.
26. Peto $R$, et al. Design and analysis of randomized clinical trials requiring prolonged observation of each patient. I. Introduction and design. Br J Cancer. 1976;34(6):585-612.

27. Langman MJ, et al. Prospective, double-blind, placebo-controlled randomized trial of cimetidine in gastric cancer. British Stomach Cancer Group. Br J Cancer. 1999:81(8):1356-62.

28. Quintero Dea. Workload optimized systems: tuning POWER7 for analytics. 1st Ed, October 2012, updated 14 April 2013.

29. Fiteni F, Westeel V, Pivot X, Borg C, Vernerey D, Bonnetain F. Endpoints in cancer clinical trials. J Visc Surg. 2014;151(1):17-22. https://doi. org/10.1016/j.jviscsurg.2013.10.001

30. Jo SD, et al. Targeted nanotheranostics for future personalized medicine: recent progress in cancer therapy. Theranostics. 2016;6(9):1362-77.

31. Dawidczyk CM, Russell LM, Searson PC. Nanomedicines for cancer therapy: state-of-the-art and limitations to pre-clinical studies that hinder future developments. Front Chem. 2014;2:69.

32. Chen LC, et al. Pharmacokinetics, dosimetry and comparative efficacy of 188Re-liposome and 5-FU in a CT26-luc lung-metastatic mice model. Nucl Med Biol. 2012;39(1):35-43.

33. Passero FC Jr, et al. The safety and efficacy of Onivyde (irinotecan liposome injection) for the treatment of metastatic pancreatic cancer following gemcitabine-based therapy. Expert Rev Anticancer Ther. 2016;16(7):697-703

34. Barenholz Y. Doxil(R)-the first FDA-approved nano-drug: lessons learned. J Control Release. 2012;160(2):117-34

35. Xing $M$, et al. Efficacy and cardiotoxicity of liposomal doxorubicin-based chemotherapy in advanced breast cancer: a meta-analysis of ten randomized controlled trials. PLoS ONE. 2015;10(7):e0133569.

36. Tampaki EC, et al. Efficacy and safety of neoadjuvant treatment with bevacizumab, liposomal doxorubicin, cyclophosphamide and paclitaxe combination in locally/regionally advanced, HER2-negative, grade III at premenopausal status breast cancer: a phase II study. Clin Drug Investig. 2018;38:639-48.

37. Tan SF, et al. Direct observation of interactions between nanoparticles and nanoparticle self-assembly in solution. Acc Chem Res. 2017:50(6):1303-12

38. Geoffrey A. Ozin1, Kun Hou1, Bettina V. Lotsch2, Ludovico Cademartiri3, Daniel P. Puzzo1, Francesco Scotognella4, Arya Ghadimi1 and Jordan Thomson1, Nanofabrication by self-assembly. Materials Today. 2009.

39. Whitesides GM, Kriebel JK, Mayers BT. Self-assembly and nanostructured materials. Nanoscale. Assembly. 2005;. https://doi.org/10.1007/0-38725656-3_9.

40. Singh VK, Saini A, Chandra R. The implications and future perspectives of nanomedicine for cancer stem cell targeted therapies. Front Mol Biosci. 2017:4:52.

41. Marhaba R, et al. CD44 and EpCAM: cancer-initiating cell markers. Curr Mol Med. 2008;8(8):784-804.

42. Vinogradov $S$, Wei X. Cancer stem cells and drug resistance: the potential of nanomedicine. Nanomedicine (Lond). 2012;7(4):597-615.

43. Sadighi $\mathrm{S}$, et al. Quality of life in patients with advanced gastric cancer: a randomized trial comparing docetaxel, cisplatin, 5-FU (TCF) with epirubicin, cisplatin, 5-FU (ECF). BMC Cancer. 2006;6:274

Ready to submit your research? Choose BMC and benefit from:

- fast, convenient online submission

- thorough peer review by experienced researchers in your field

- rapid publication on acceptance

- support for research data, including large and complex data types

- gold Open Access which fosters wider collaboration and increased citations

- maximum visibility for your research: over 100M website views per year

At BMC, research is always in progress.

Learn more biomedcentral.com/submissions 